\title{
ANALYSIS OF SYMMETRICAL \& ASYMMETRICAL PWM BASED THREE PHASE AC TO AC CONVERTER FOR POWER QUALITY IMPROVEMENT
}

\author{
Venkatesha $\mathrm{K}^{\mathbf{1}}$, Vidya $\mathrm{H} \mathrm{A}^{\mathbf{2}}$ \\ ${ }^{1}$ Associate Professor, Dept. of Electrical \& Electronics Engineering, BNM Institute of Technology, Karnataka, \\ Bangalore, India \\ ${ }^{2}$ Professor \& HOD, Dept. of Electrical \& Electronics Engineering, Global Academy of Technology, Karnataka, \\ Bangalore, India
}

\begin{abstract}
A Three phase bidirectional AC to AC buck converter circuit using power MOSFET operating in high frequency chopping mode is simulated and analyzed for electrical parameters such as output phase voltage, input line current, input power factor, harmonic profile and efficiency using MATLAB/simulink software package. The various PWM techniques such as symmetrical ramp-DC PWM (SRDPWM), asymmetrical ramp-triangular PWM (ARTPWM), asymmetrical sinusoidal PWM type-1 [ASPWM1] and asymmetrical sinusoidal PWM type-2 [ASPWM2] techniques are adopted to analyze the harmonic profile, input power factor and efficiency of the converter. The rms value of the output phase voltage, output line current and source current can be significantly increased by varying the duty ratio $K$ in case of symmetrical PWM control strategy and modulation index MI in case of asymmetrical PWM control strategies independent of variation in switching frequency. It is observed from the simulation results that the ASPWM1 switching strategy gives more output phase voltage, input power factor, efficiency by increasing modulation index MI and reduced low order harmonics of output voltage and source current by increasing the number of pulses per half cycle $\boldsymbol{P}$ compared to other PWM techniques rendering easy and economical filteration.
\end{abstract}

Keywords: Three phase AC chopper, symmetrical ramp-DC PWM, asymmetrical ramp-triangular PWM, asymmetrical sinusoidal PWM technique, harmonic profile, power factor, efficiency

\section{INTRODUCTION}

Industrial loads such as heaters, illumination control, furnaces, AC motor speed control and also theatre dimmers uses AC voltage controllers. Such voltage regulators, however, have slow response, poor input power factor, and high magnitude of low order harmonic at both input and output sides. These converters need large input-output filters to reduce low order harmonics in the line current. These drawbacks have been overcome by designing various topologies of AC chopper [1-8]. In most standard AC choppers, the commutation causes high voltage spikes and an alternative current path has to be provided when current paths are changed. This alternative current path is implemented using additional bidirectional switches [3]. Such topologies are difficult and expensive to realize and the voltage stress of the switch is also high, resulting in reduced reliability.

The harmonic analysis and power factor improvement are the two important parameters to be considered in $\mathrm{AC}$ to $\mathrm{AC}$ converter circuits [9]. It is required to select the modern PWM technique which gives best performance of the converter with respect to improved input power factor and reduced harmonic content in both input current \& output voltages. In this paper, a three phase bidirectional AC buck converter is proposed and analyzed for three phase star connected RL load using symmetrical ramp-DC PWM (SRDPWM), asymmetrical ramp-triangular PWM (ARTPWM), asymmetrical sinusoidal PWM type-1 [ASPWM1] and asymmetrical sinusoidal PWM type-2 [ASPWM2] techniques. In case of SRDPWM technique, duty ratio $\mathrm{K}$ is varied in order to vary the power flow, better harmonic profile and efficiency of the three phase converter. Whereas in case of ARTPWM, ASPWM1 and ASPWM2 technique, the modulation index $\mathrm{MI}$ is varied in order to change the power flow, harmonic profile, power factor and efficiency of the three phase convert. But the number of pulses per half cycle $(\mathrm{P})$ is increased in both symmetrical and asymmetrical PWM techniques in order to change the entire harmonic profile of the output phase voltage and input source current. The change in switching frequency has no effect on output phase voltage, output line current and source current variation in both symmetrical and asymmetrical control strategies. 


\section{OPERATION OF THE CONVERTER}

\section{TOPOLOGY}

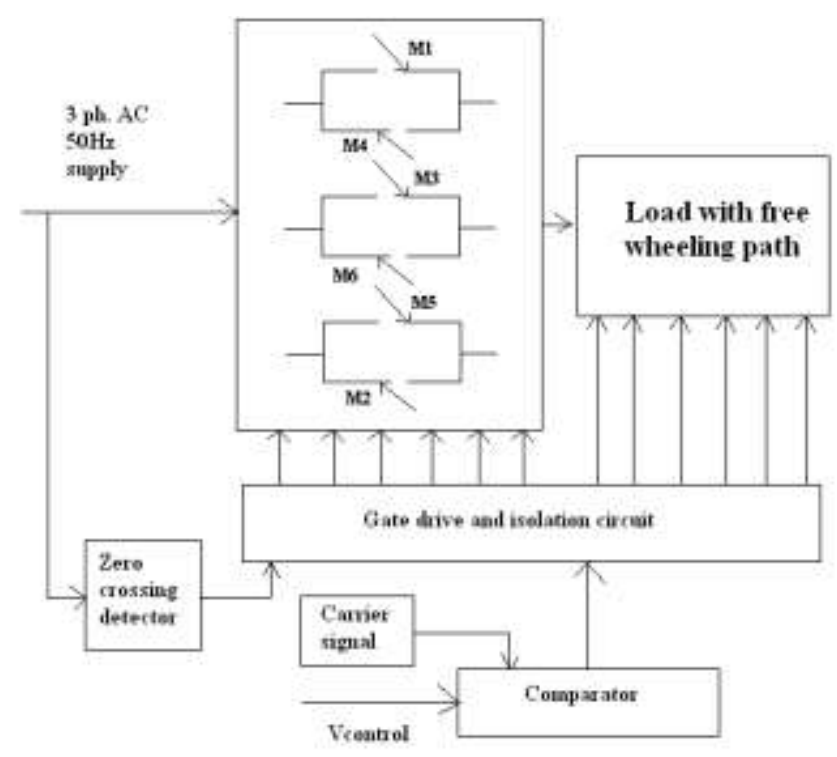

Fig. 1 Block diagram of three phase $\mathrm{AC}$ to $\mathrm{AC}$ converter

Fig.1 shows the block diagram of three phase AC to AC buck converter with control circuit to generate pulses to power MOSFET embedded four quadrant switches operating in high frequency chopping mode. The control circuit comprises of comparator that compares carrier signals such as ramp or triangular signal with control or reference signals such as DC, negative ramp and sine wave signals. The carrier wave remains same for all the three phases. But three reference waves which are $120^{\circ}$ apart are taken to compare with common carrier waveform in order to generate the PWM pulses. The logical operation takes place between PWM pulses and zero crossing detector pulses which are tapped from three phase supply in order to generate switching pulses to trigger the particular switching set during positive and negative half cycles respectively. The duty ratio $\mathrm{K}$ can be increased in order to vary all the electrical parameters including harmonic profile. Whereas $\mathrm{P}$ can be varied in order to vary the harmonic profile of the converter. The technique continues to evoke interest with respect to variation of $\mathrm{P}$ and $\mathrm{K}$ [8]. The chopped output voltage waveform is analyzed for harmonic content for various values of $\mathrm{P} \& \mathrm{~K}$. This technique can be adopted for the harmonic content reduction at the high frequency chopping mode facilitating easy filtration at lower cost.

Fig. 2 shows the three phase Buck AC chopper that uses four quadrant bidirectional switches. The combination of switches M1 with series diode D1 and M4 with series diode D4 forms one set of four quadrant switch for modulating purpose. Similarly the switch combination M8 with series diode D8 and M7 with series diode D7 forms another four quadrant switch set for freewheeling operation across RL loads of phase 'A'.
The control of the switches is based on the different modern PWM techniques. In practical realizations of the converter, stray inductances increase the voltage stress of the bidirectional switches and may destroy the switches. This situation requires the converter using $\mathrm{AC}$ snubber comprising RC combination (Rs and Cs).

The configuration of the three phase buck ac chopper feeding star connected RL load involves regeneration, power absorption by the load and freewheeling. Each switch conducts for 180 degrees. At any instant of time, three switches are modulated and three switches are additionally turned on for regeneration or freewheeling operation. The commutation policy is that the switches M2, M3 and M4 for Vs $>0$ are additionally turned on for 60 degrees during which switch M1 is modulated. The modulating signal changes for every 60 degrees so that at any instant three switches will conduct. The switching pattern is 5-6-1, 6-1-2, 1-2-3, 2-3-4, 3-4-5, 4-5-6 and back to 5-6-1 after one cycle. The other switches are additionally turned on for giving path for an inductor current. If the load inductor current $i_{L}$ is positive, the inductor current is bypassed or freewheeled through freewheeling switches available in parallel to the load. If the load inductor current is negative, then it bypasses to the source through the input side switches. The enhancement type MOFSETs are used in converters as switching devices due to their high switching frequency greater than $1 \mathrm{MHz}$, and is available with forward blocking voltage and current of $1000 \mathrm{~V}$ and $40 \mathrm{~A}$ respectively. The operation of power switching devices at higher frequencies results in decreased size of inductors and filter capacitors that facilitates compact and economical power electronic systems. Fig. 3 shows the switching pattern for the four forced commutated switches of the three phase buck AC chopper. The dead-time is requisite to avoid current spikes of practical non-ideal switches and at the same time a current path of the inductive load has to be provided to avoid voltage spikes. The modulating pulses can be symmetrical or asymmetrical which depends on the type of PWM technique. But the logical operation remains same for all the PWM techniques.

\section{MERITS OF AC TO AC CONVERTER CIRCUITS}

The merits of $\mathrm{AC}$ to $\mathrm{AC}$ converter circuit are the reduced lower order harmonics at both input and output side. Sinusoidal input currents with nearly unity input power factor can be achieved with the help of input filters. Sinusoidal output currents with RL loads without filters. The higher switching frequency selection results in reduction of filter size. AC chopper does not require gating signals synchronous with the line voltage. Faster dynamic response with respect to sag and swell correction and high efficiency of the converter can be achieved. 


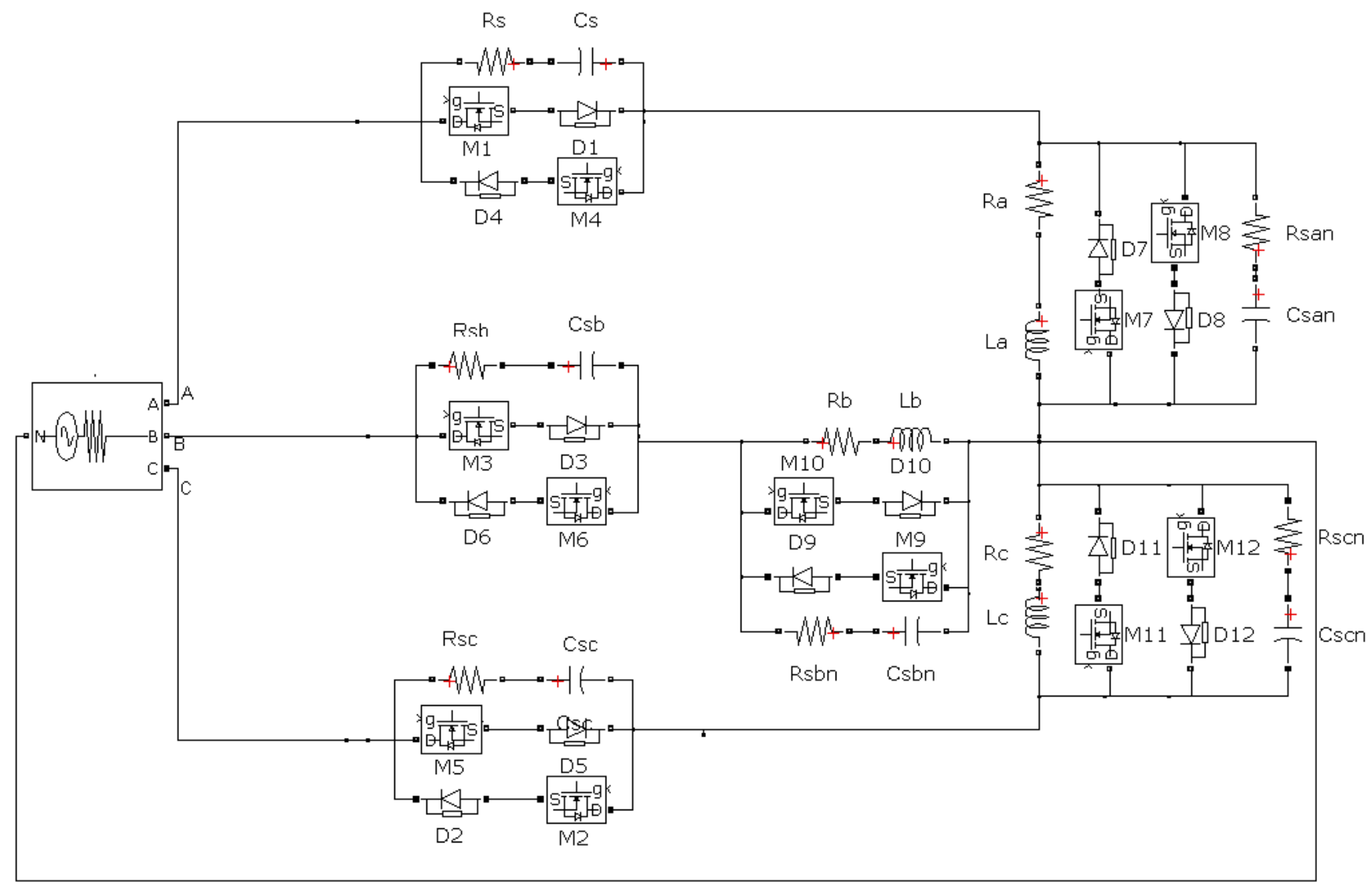

Fig. 2 Three phase buck converter circuit diagram for three phase star connected RL load

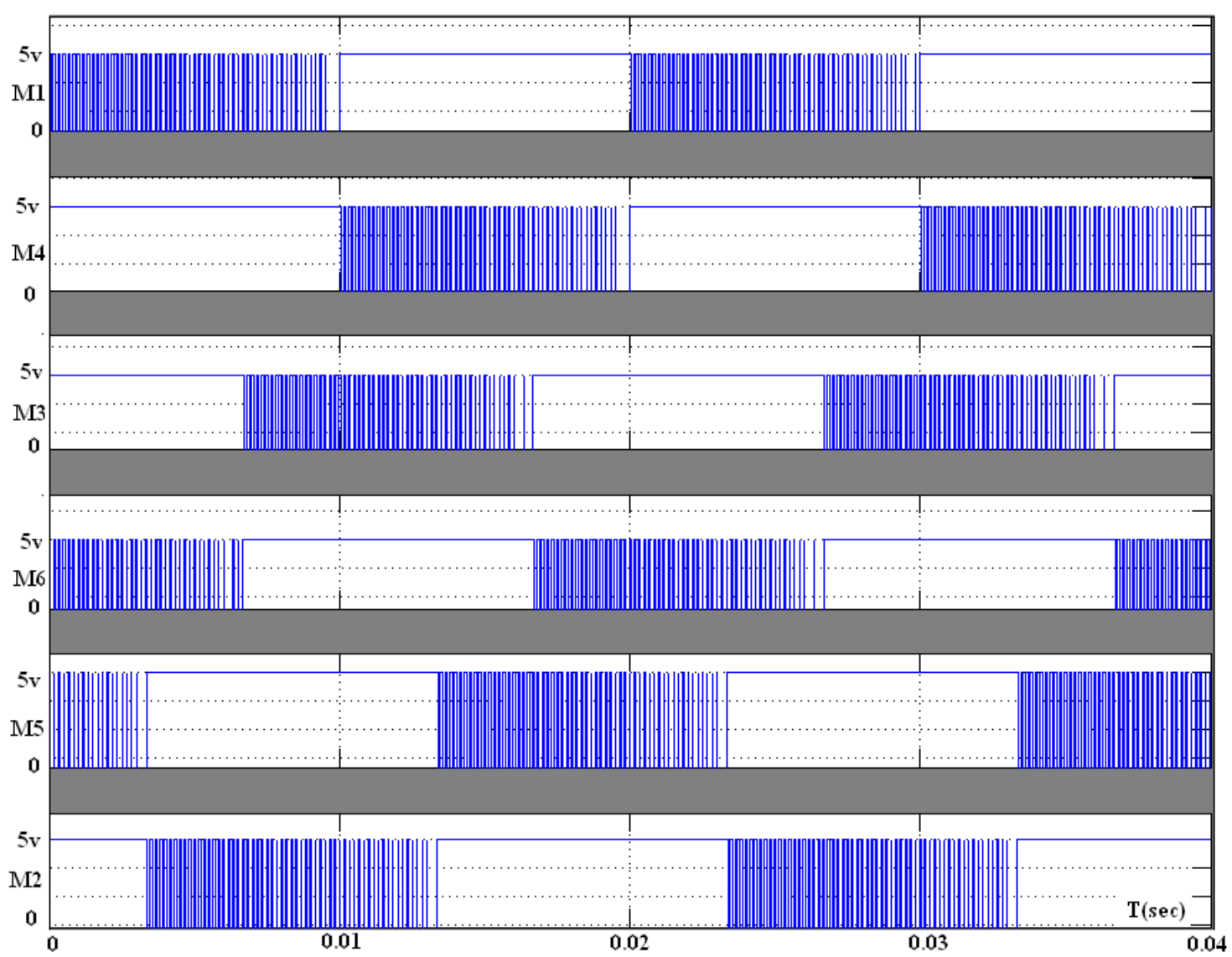

Fig. 3a Switching pattern for the line MOSFET switches M1 to M6 of three phase buck converter 


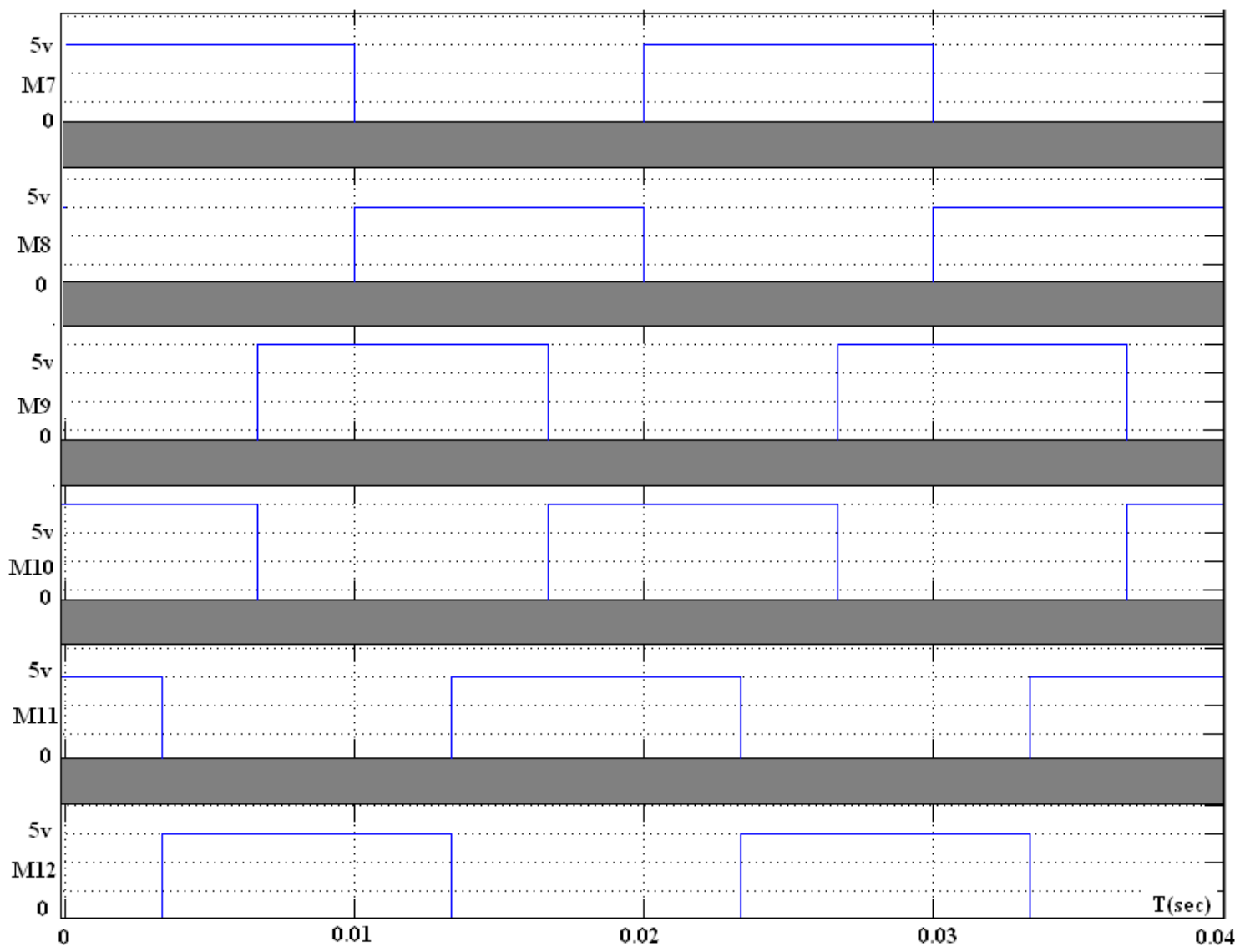

Fig. 3b Switching pattern for load side MOSFET switches M7 to M12 of three phase star connected load.

\section{VARIOUS PWM SWITCHING PATTERNS}

The various PWM switching techniques selected for AC chopper are analyzed for input power factor, harmonic profile and efficiency of the converter circuit.

\subsection{Symmetrical Ramp-DC PWM (SRDPWM)}

In the SRDPWM control strategy as shown in Fig.4, the switching pulses are generated by comparing ramp with DC voltage. The carrier signal ramp having peak value of $10 \mathrm{~V}$ is varied for different switching frequencies like $4.2 \mathrm{KHz}$, $4.8 \mathrm{KHz}, 5.4 \mathrm{KHZ}$ and $6 \mathrm{KHz}$. The DC reference or control signal is varied from $4 \mathrm{~V}$ to $9 \mathrm{~V}$ in order to get duty ratio from 0.4 to 0.9 . The control circuit comprises of ramp pulse generator of desired frequency which is compared with the variable DC voltage $\mathrm{V}_{\text {control }}$ to generate switching pulses. The ZCD pulses are obtained by stepping down the three phase voltages and then passed through the zero crossing detectors. The PWM pulses and ZCD pulses of phases A, B $\& \mathrm{C}$ are ORed to generate switching pulses for six switches of the three phase converter as shown in Fig. 3a. The ZCD and inverted ZCD pulses are fed to the freewheeling switches connected across the RL load as shown in Fig. 3b. The number of pulses per half cycle $\mathrm{P}$ can be calculated as

$P=\frac{F_{S}}{2 F}$
The duty ratio is defined as

$K=\frac{t_{\text {on }}}{T_{s}}$

Where

$\mathrm{F}_{\mathrm{s}}$ : Switching frequency in $\mathrm{Hz}$.

$\mathrm{F}$ : Fundamental or supply frequency $\mathrm{n} \mathrm{Hz}$

$\mathrm{t}_{\mathrm{on}}$ : On time of switching pulses in secs.

$\mathrm{T}_{\mathrm{s}}$ : Total Switching time in secs.

Vramp(volts) Vcontrol(volts)
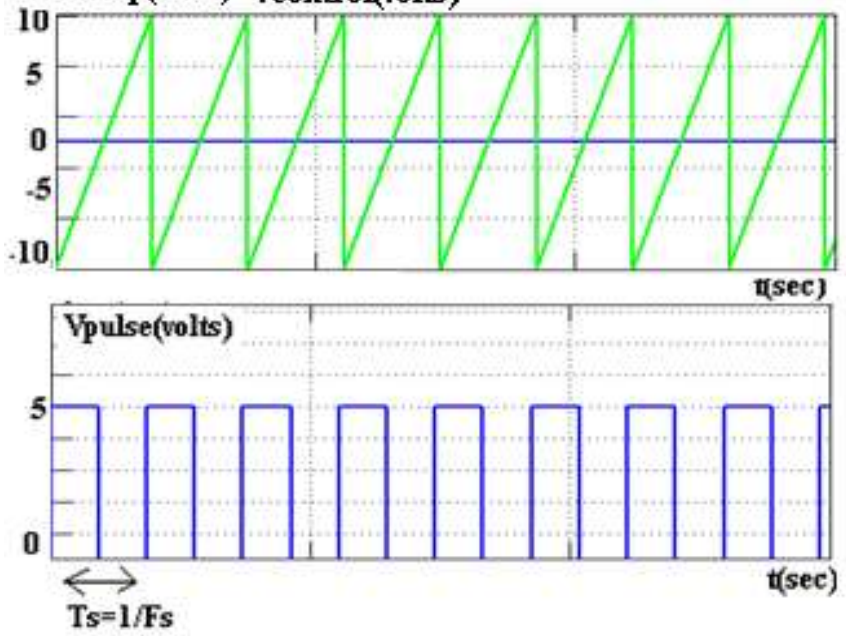

Fig.4 SRDPWM technique and the corresponding switching pulses 


\subsection{Asymmetrical Ramp-Triangular PWM}

\section{(ARTPWM)}

In the ARTPWM control strategy of a three phase ac chopper, the switching pulses are generated by comparing three different negative slope ramps which are electrically displace by $120^{\circ}$ with common triangular carrier signal in order to generate the pulses. The peak to peak value of triangular waveform is $20 \mathrm{~V}$. The ZCD pulses are obtained by stepping down the three phase voltages and then passed through the zero crossing detectors. The PWM pulses and ZCD pulses are ORed to generate switching pulses for six switches of the three phase converter. The ZCD and inverted ZCD pulses are fed to the freewheeling diodes that are connected across the RL load. The triangular waveform is varied for different switching frequencies like $4.2 \mathrm{KHz}, 4.8$ $\mathrm{KHz}, 5.4 \mathrm{KHZ}$ and $6 \mathrm{KHz}$. The negative ramp signal peak value is varied from $4 \mathrm{~V}$ to $9 \mathrm{~V}$ with different slopes in order to vary the MI in linear region from 0.4 to 0.9 . The ratio of peak value of ramp to the peak value of triangular signal is named as modulation index MI. The definition of modulation index is

$\mathrm{MI}=\frac{\mathrm{V}_{\text {ramp }- \text { peak }}}{\mathrm{V}_{\text {tri }- \text { peak }}}$

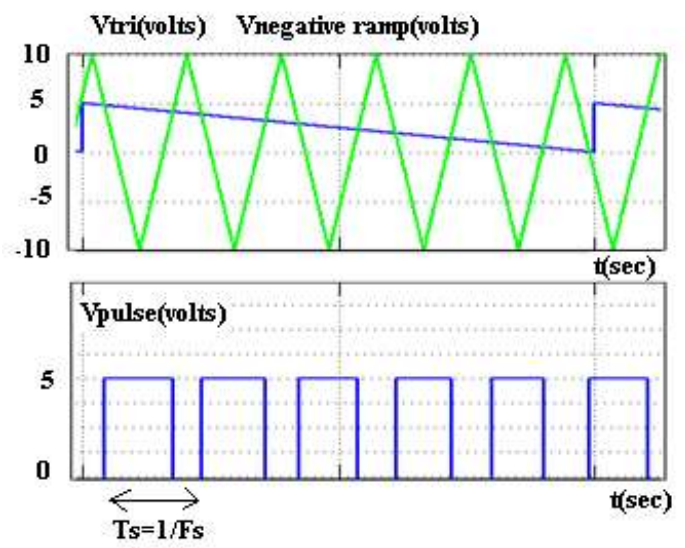

Fig.5 ARTPWM technique and the corresponding switching pulses

\subsection{Asymmetrical Sinusoidal PWM type-1 [ASPWM1]}

In the ASPWM1 control strategy of a three phase ac chopper, the switching pulses are generated by comparing three different unidirectional AC signal [displaced by $120^{\circ}$ ] with triangular signal as shown in Fig.6. The peak to peak value of triangular waveform is $20 \mathrm{~V}$. The ZCD pulses are obtained by stepping down the three phase voltages and then passed through the zero crossing detectors. The PWM pulses and ZCD pulses are ORed to generate switching pulses for six switches of the three phase converter. The ZCD and inverted ZCD pulses are fed to the freewheeling switches connected across the RL load as shown in Fig. 3b. The triangular waveform is varied for different switching frequencies like $4.2 \mathrm{KHz}, 4.8 \mathrm{KHz}, 5.4 \mathrm{KHZ}$ and $6 \mathrm{KHz}$. The control signal sine wave peak value is varied from $4 \mathrm{~V}$ to $9 \mathrm{~V}$ in order to vary the $\mathrm{MI}$ in linear region from 0.4 to 0.9 . The ratio of peak value of sine wave to the peak value of triangular signal is named as modulation index MI. The definition of modulation index is

$$
M I=\frac{V_{\text {sine }- \text { peak }}}{V_{\text {tri }- \text { peak }}}
$$

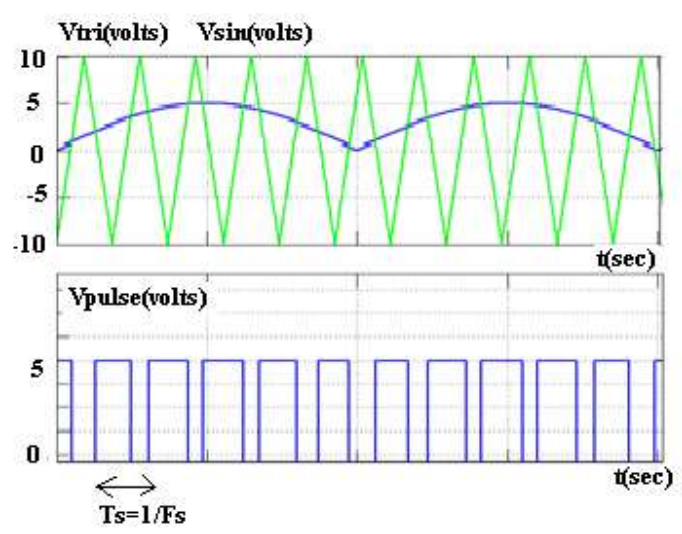

Fig.6

ASPWM1 technique and the corresponding switching pulses

\subsection{Asymmetrical Sinusoidal PWM type2 [ASPWM2]}

In the ASPWM2 control strategy of a three phase ac chopper, the switching pulses are generated by comparing unidirectional AC signal with positive triangular signal whose peak value is $10 \mathrm{~V}$ as shown in Fig.7. The peak value of control signal which is unidirectional sine wave is varied from $4 \mathrm{~V}$ to $9 \mathrm{~V}$ in order to vary $\mathrm{MI}$ in linear region from 0.4 to 0.9 . The ZCD pulses are obtained by stepping down the three phase voltages and then passed through the zero crossing detectors. The PWM pulses and ZCD pulses are ORed to generate switching pulses for six switches of the three phase converter. The ZCD and inverted ZCD pulses are fed to freewheeling switches that are connected across RL load as shown in Fig. 3b. The ratio of peak value of sine wave to the triangular signal is named as modulation index MI. The definition of modulation index is

$$
M I=\frac{V_{\text {sine }- \text { peak }}}{V_{\text {tri-peak }}}
$$

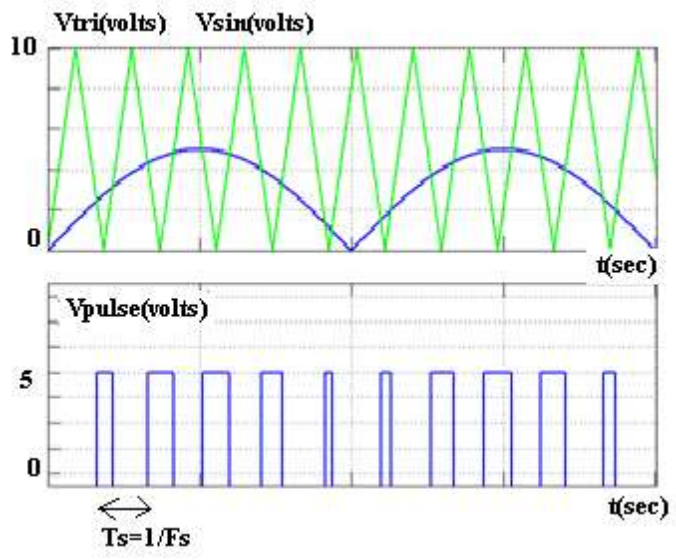

Fig.7 ASPWM2 technique and the corresponding switching pulses 


\section{SIMULATION OF AC TO AC CONVERTER CIRCUIT}

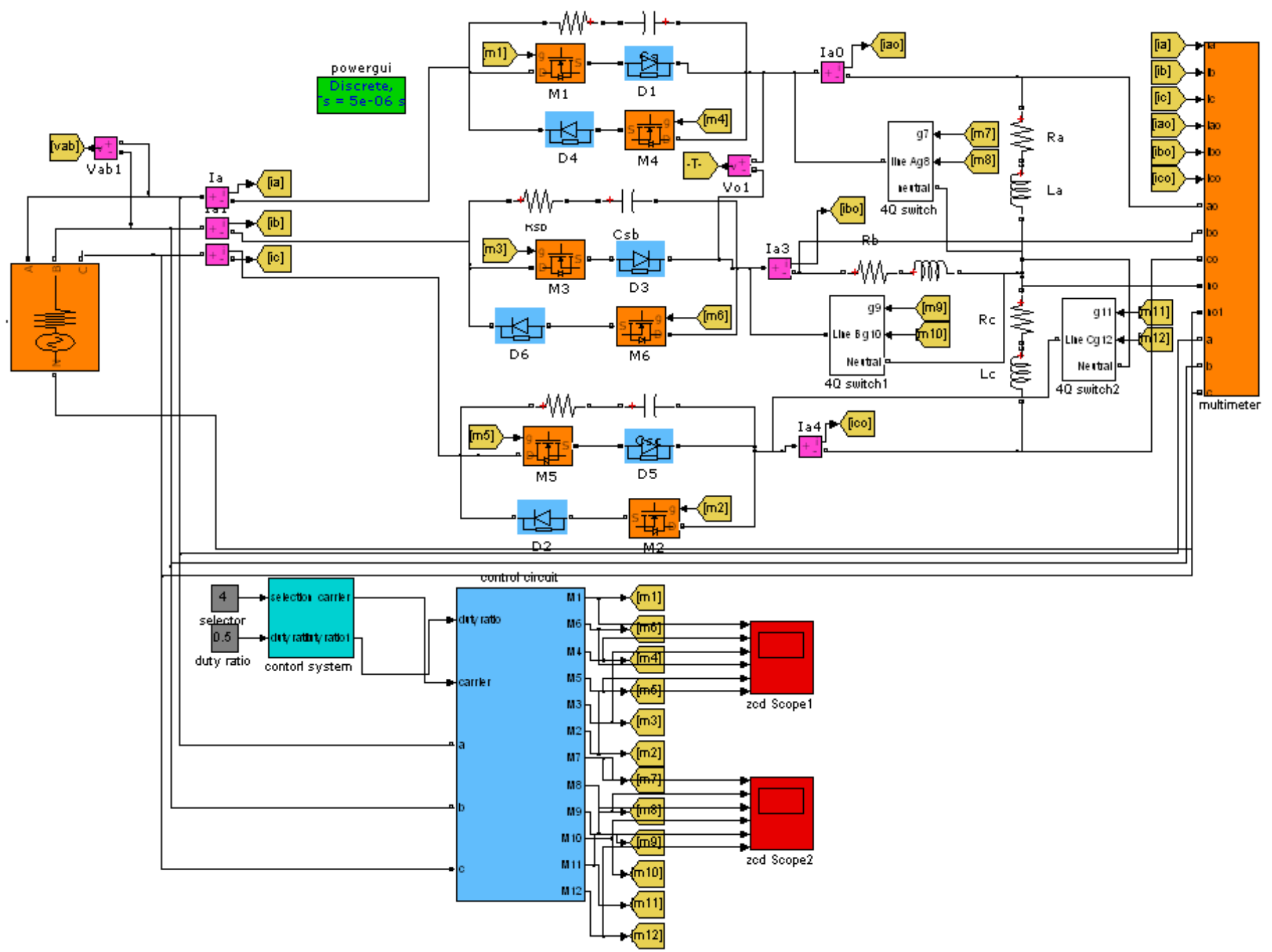

Fig. 8 Simulation circuit of three phase AC to AC converter built using MATLAB/simulink software package.

The Harmonic profile, input power factor and efficiency of the three phase converter is investigated using MATLAB/simulink. The three phase buck AC chopper with AC snubber simulation model is as shown in Fig. 8. The system characteristics are input line voltage $\mathrm{V}_{\mathrm{L}}=400 \mathrm{~V}$, $50 \mathrm{~Hz}$ supply, semiconductor element MOSFET IRFPE40, snubber elements $\mathrm{R}_{\mathrm{s}}=5.4 \mathrm{~K} \Omega \& \mathrm{C}_{\mathrm{s}}=3 \mathrm{nF}$, load parameters are $\mathrm{R}_{\mathrm{o}}=529 \Omega \mathrm{L}_{\mathrm{o}}=0.9 \mathrm{H}$. The Switching frequency $\mathrm{F}_{\mathrm{s}}$ is varied from $4.2 \mathrm{KHz}$ to $6 \mathrm{KHz}$ and corresponding $\mathrm{P}$ is varied from 42 to 60 pulses per half cycle which is related as given in equation (1). The harmonic order up to $100^{\text {th }}$ order is considered in the analysis. The harmonic components present in the source current and output phase voltage are dependent on $\mathrm{P}$ as $\mathrm{nP} \pm 1$. Where $\mathrm{n}$ is an even number. For instance, if $\mathrm{P}=42 \quad\left[\mathrm{~F}_{\mathrm{s}}=4.2 \mathrm{~Hz}\right]$, then the order of the harmonics present are $2 \mathrm{P} \pm 1,4 \mathrm{P} \pm 1$ etc [harmonic order 83 , $85,167,169]$. In this way selective harmonic elimination can be done by selecting the proper value of $\mathrm{P}$. Therefore for $\mathrm{P}=42$, harmonic order up to $82^{\text {nd }}$ order can be eliminated in the output phase voltage and source current.
The input side parameters like input phase voltage, source current are sensed to calculate input side rms values, input power factor and input power using sub models. Similarly output side parameters like output phase voltage and current are sensed to calculate their rms values, output power and power factor by using sub models. Hence, the power factor $\mathrm{PF}$ is modeled using the general definition as given in equation (6).

Using all these parameters, the efficiency of the three phase balanced converter can be calculated as per equation (7) using sub models and displayed using numeric displays.

$$
\begin{gathered}
P F=\frac{P_{\mathrm{s}}}{\mathrm{s}}=\frac{P_{\mathrm{s}}}{V_{r m s} I_{r m s}} \\
=\frac{\frac{1}{\mathrm{~T}} \int_{0}^{\mathrm{T}} \mathrm{v}_{\mathrm{s}}(\mathrm{t}) \mathrm{i}_{\mathrm{s}}(\mathrm{t}) \mathrm{dt}}{\sqrt{\frac{1}{\mathrm{~T}} \int_{0}^{\mathrm{T}} \mathrm{v}^{2}{ }_{\mathrm{s}}(\mathrm{t}) \mathrm{dt}} \sqrt{\frac{1}{\mathrm{~T}} \int_{0}^{\mathrm{T}} \mathrm{i}^{2}{ }_{\mathrm{s}}(\mathrm{t}) \mathrm{dt}}}
\end{gathered}
$$

The efficiency can be calculated as 
$\eta=\frac{P_{o}}{P_{s}}=\frac{\frac{1}{T} \int_{0}^{T} v_{o}(t) i_{o}(t) d t}{\frac{1}{T} \int_{0}^{T} v_{s}(t) i_{s}(t) d t}$

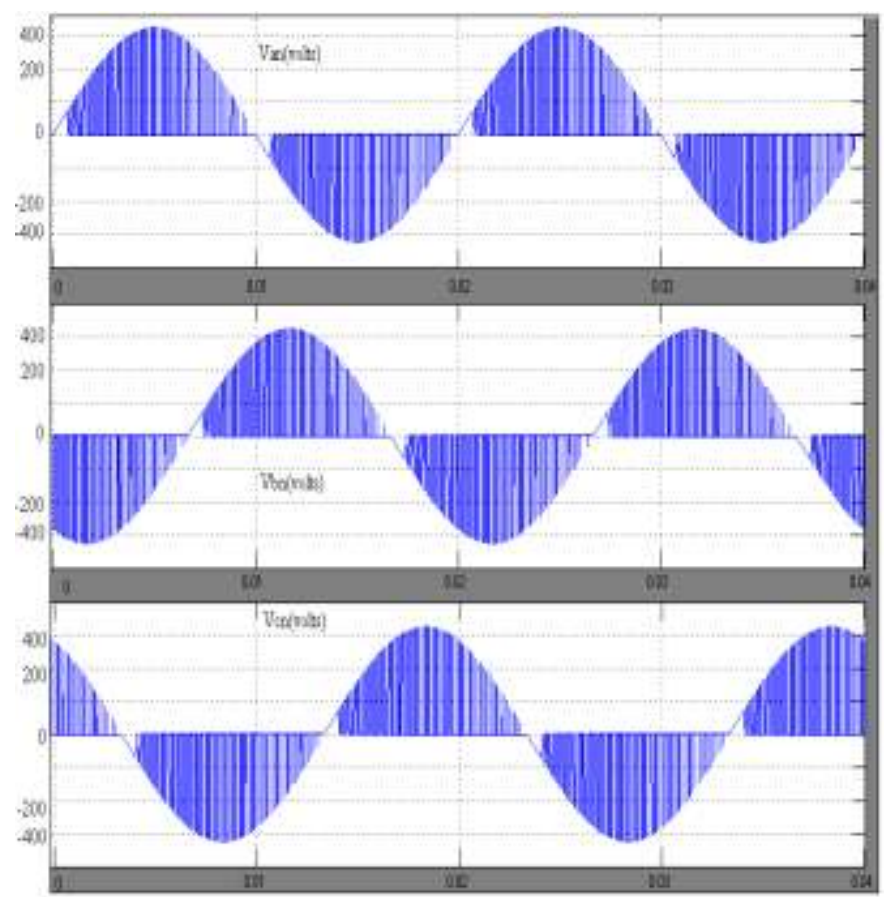

Fig.9 Waveforms of three phase output voltage for duty ratio $\mathrm{K}=0.5$ and $\mathrm{P}=60\left[\mathrm{~F}_{\mathrm{s}}=6 \mathrm{KHz}\right]$

Fig.9 shows the waveforms of output phase voltages $V_{a n}$, $\mathrm{V}_{\mathrm{bn}}$ and $\mathrm{V}_{\mathrm{cn}}$ using SRDPWM switching pattern. The output line currents $I_{A}, I_{B}$ and $I_{C}$ are sinusoidal in nature for inductive load as shown in Fig. 10. In this case freewheeling operation is considered and proper path is provided for inductive load current irrespective of positive or negative value by turning on the additional switches. The output current is almost a sine wave without ripple content due to freewheeling operation of inductive load. For $\mathrm{Vs}>0$, the positive inductive load current passes through freewheeling bidirectional switches and negative inductive load current passes through the source.

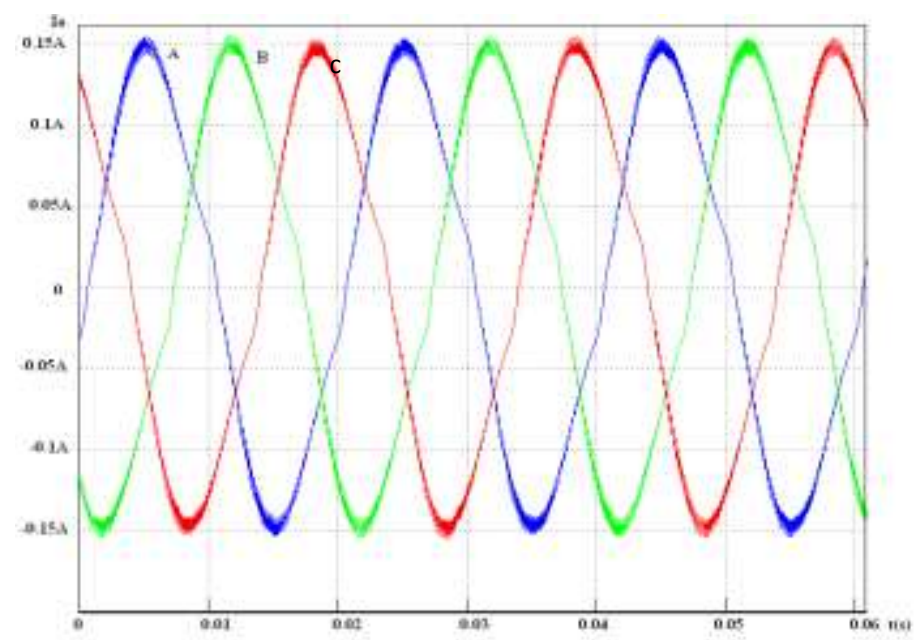

Fig.10 Waveforms of three phase output currents for $\mathrm{P}=60$ $\left[\mathrm{F}_{\mathrm{s}}=6 \mathrm{KHz}\right]$

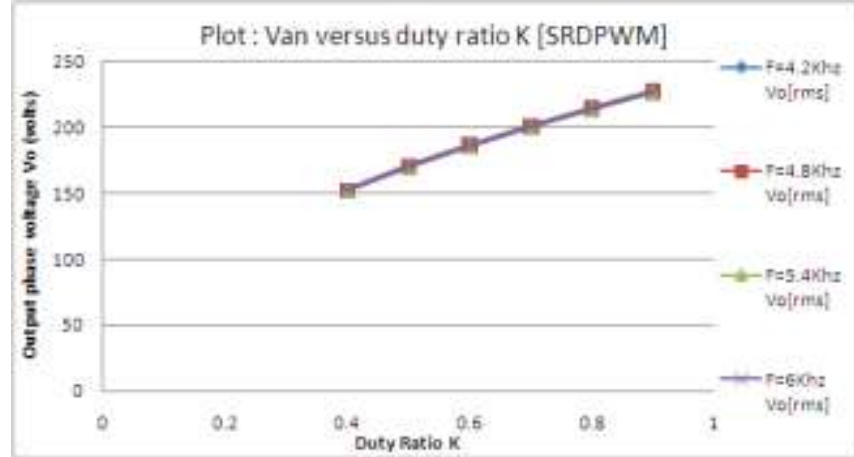

Fig.11 Plot of output phase voltage $V_{\text {an }}$ versus duty ratio for different switching frequency using SRDPWM technique

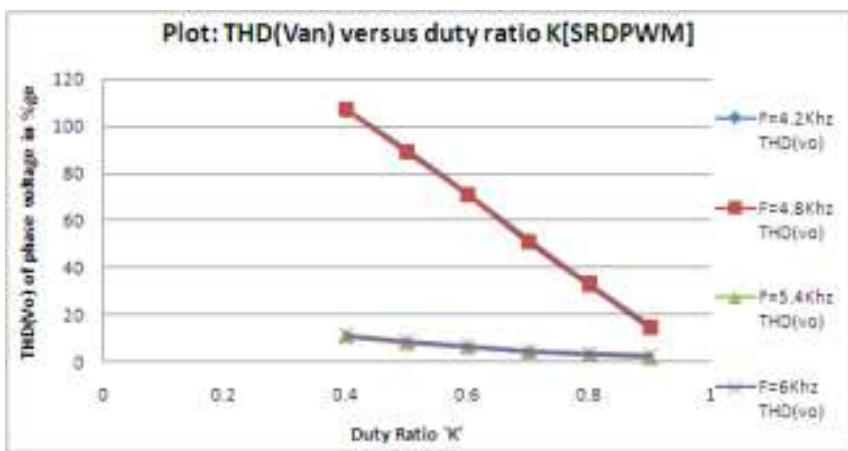

Fig.12 Plot of $\operatorname{THD}\left(\mathrm{V}_{\mathrm{an}}\right)$ output phase voltage versus duty ratio $\mathrm{K}$ for different switching frequency using SRDPWM technique

Fig.11 indicates the plot of output phase voltage $V_{\text {an }}$ with respect to the variation of duty ratio $\mathrm{K}$. It is observed that the output phase voltage $V_{\text {an }}$ remains same irrespective of the switching frequency variation. The harmonic profile changes with the increase in duty ratio as shown in Fig. 12. The $\operatorname{THD}\left(\mathrm{V}_{\mathrm{an}}\right)$ predominantly reduces with respect to increase in number of pulses per half cycle $\mathrm{P}$ or switching frequency $F_{s}$. For instance, selecting $P=60$ or $F_{s}=6 \mathrm{KHz}$ in SRDPWM technique, up to $119^{\text {th }}$ harmonic order are eliminated and hence the $\operatorname{THD}\left(\mathrm{V}_{\mathrm{o}}\right)$ at $\mathrm{K}=0.9$ is $2.57 \%$. But as the switching frequency is increased, the efficiency of the converter decreases due to switching losses as shown in Fig.13. The characteristics of these plots are similar in all the PWM techniques.

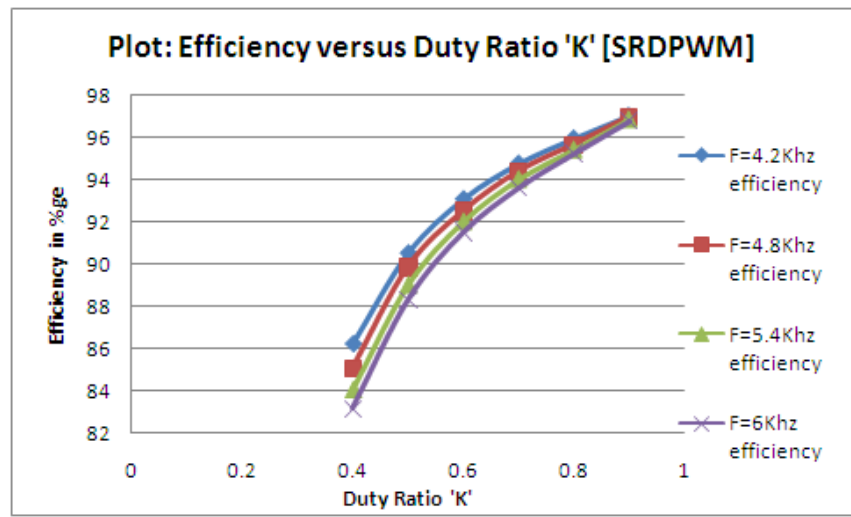

Fig.13 Plot of efficiency versus duty ratio $\mathrm{K}$ for different switching frequency using SRDPWM technique 
Fig.14 \& Fig.15 indicates the harmonic profile of various PWM switching patterns at switching frequency $\mathrm{F}_{\mathrm{s}}=6 \mathrm{KHz}$. The THD of the output phase voltage is maximum in case of ASPMW2 type $\left[\operatorname{THD}\left(\mathrm{V}_{\mathrm{o}}\right)=20.5 \%\right.$ for $\mathrm{K}=0.4$ to $18.5 \%$ for $\mathrm{K}=0.9$ ] and minimum in case of SRDPWM technique $\left[\operatorname{THD}\left(\mathrm{V}_{\mathrm{o}}\right)=11.11 \%\right.$ for $\mathrm{K}=0.4$ to $2.57 \%$ for $\left.\mathrm{K}=0.9\right]$. Similarly The THD of the source current is maximum in case of ASPMW2 type $\left[\operatorname{THD}\left(\mathrm{I}_{\mathrm{s}}\right)=26.73 \%\right.$ for $\mathrm{K}=0.4$ to $29.08 \%$ for $\mathrm{K}=0.9$ ] and minimum in case of SRDPWM technique $\left[\operatorname{THD}\left(\mathrm{I}_{\mathrm{s}}\right)=13.52 \%\right.$ for $\mathrm{K}=0.4$ to $5.24 \%$ for $\mathrm{K}=0.9$ ]. The ARTPWM and ASPMW1 techniques are better than the ASPMW2 technique with respect to THD of output voltage and source current variation. These techniques have better harmonic profile from $\mathrm{K}=0.4$ to 0.6 . But there is almost constant or slight increase in THD values with respect to variation of MI in these cases. Hence SRDPWM technique is better with respect to harmonic profile than other techniques with respect to variation of duty cycle $K=0.6$ onwards.

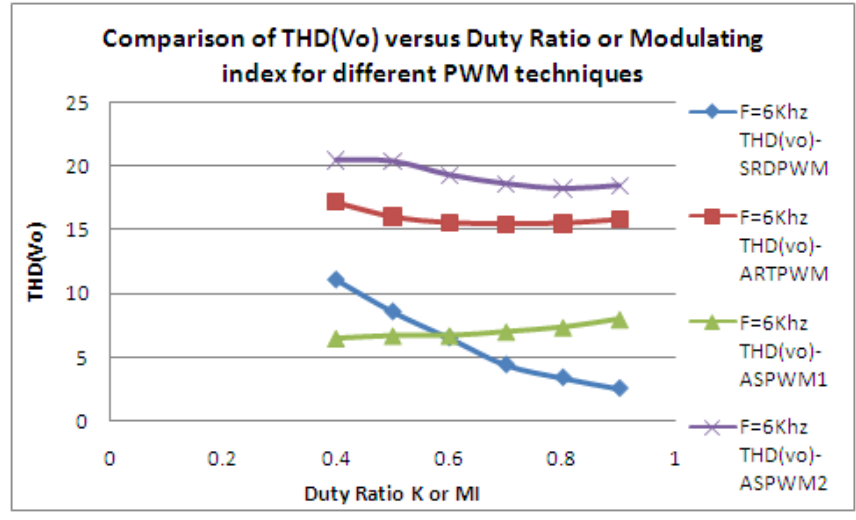

Fig.14 Plot of THD $\left(V_{\text {an }}\right)$ versus duty ratio for different PWM technique with constant switching frequency of $6 \mathrm{KHz}$

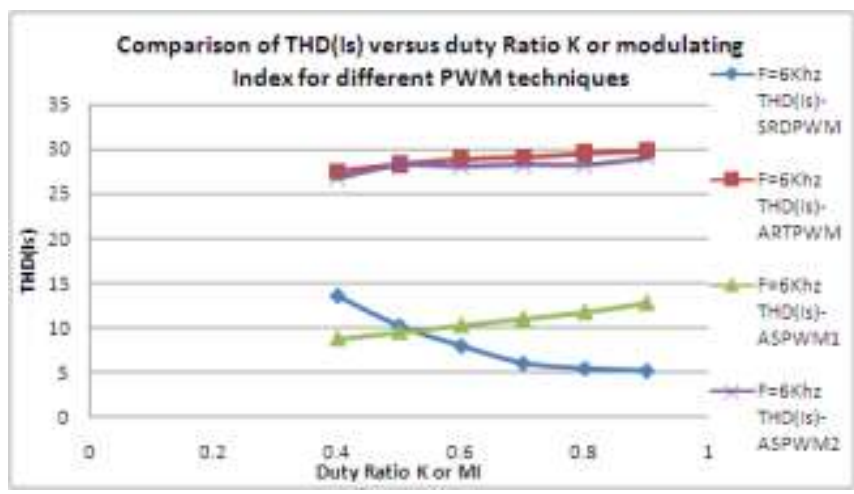

Fig.15 Plot of THD $\left(I_{s}\right)$ input line current versus duty ratio $K$ for different PWM technique with constant switching frequency of $6 \mathrm{KHz}$

Table-1 Analysis of power factor and efficiency with respect to duty ratio/MI for different PWM techniques

\begin{tabular}{|c|c|c|c|c|c|c|c|c|}
\hline K & $\begin{array}{c}\mathrm{F}=6 \mathrm{Khz} \\
\text { PF- } \\
\text { SRDPWM }\end{array}$ & $\begin{array}{c}\mathrm{F}=6 \mathrm{Khz} \\
\text { PF- } \\
\text { ARTPWM }\end{array}$ & $\begin{array}{c}\mathrm{F}=6 \mathrm{Khz} \\
\text { PF- } \\
\text { ASPWM1 }\end{array}$ & $\begin{array}{c}\mathrm{F}=6 \mathrm{Khz} \\
\text { PF- } \\
\text { ASPWM2 }\end{array}$ & $\begin{array}{c}\mathrm{F}=6 \mathrm{Khz} \\
\text { efficiency } \\
\text { SRDPWM }\end{array}$ & $\begin{array}{c}\mathrm{F}=6 \mathrm{Khz} \\
\text { efficiency } \\
\text { ARTPWM }\end{array}$ & $\begin{array}{c}\mathrm{F}=6 \mathrm{Khz} \\
\text { efficiency } \\
\text { ASPWM1 }\end{array}$ & $\begin{array}{c}F=6 \mathrm{Khz} \\
\text { efficiency } \\
\text { ASPWM2 }\end{array}$ \\
\hline 0.4 & 0.62 & 0.55 & 0.76 & 0.607 & 83.16 & 61.03 & 93 & 78.87 \\
\hline 0.5 & 0.67 & 0.576 & 0.78 & 0.652 & 88.3 & 69.77 & 93.83 & 85 \\
\hline 0.6 & 0.72 & 0.605 & 0.8 & 0.7 & 91.5 & 76.26 & 94.6 & 88.9 \\
\hline 0.7 & 0.76 & 0.635 & 0.82 & 0.741 & 93.6 & 80.98 & 95.3 & 91.56 \\
\hline 0.8 & 0.81 & 0.664 & 0.84 & 0.783 & 95.22 & 84.5 & 95.96 & 93.48 \\
\hline 0.9 & 0.85 & 0.693 & 0.86 & 0.823 & 96.75 & 87.2 & 96.76 & 95.1 \\
\hline
\end{tabular}

Table-1 indicates that the input power factor of the three phase converter is more in case of ASPMW1 technique $[\mathrm{PF}=0.76$ to 0.86$]$ for the variation of $\mathrm{MI}$ from 0.4 to 0.9 . Even though harmonic profile is better in case of SRDPWM technique, since the input power factor is more in case of ASPMW1 technique, the overall efficiency of the converter is better using this technique. Therefore it is required to consider both harmonic profile and power factor in order to observe the overall efficiency of the three phase converter. Hence ASPWM1 technique is being recommended for this converter for better input power factor and efficiency of the converter.

\section{CONCLUSION}

A three phase bidirectional AC to AC buck converter is simulated and analyzed for electrical parameters such as output phase voltage, input current, input power factor, harmonic profile and efficiency using MATLAB/simulink software package. The various PWM techniques such as SRDPWM, ARTPWM, ASPWM1 and ASPWM2 techniques are adopted to analyze the three phase buck converter behavior. The rms value of the output phase voltage, output current and source current can be significantly increased by varying the duty ratio $\mathbf{K}$ in case of symmetrical PWM control strategy and modulation index MI in case of asymmetrical PWM control strategies independent of variation in switching frequency. It is observed from the simulation results that the ASPWM1 switching strategy gives more output phase voltage, input power factor, efficiency by increasing MI and reduced low order harmonics of output phase voltage and source current by increasing the number of pulses per half cycle $\mathbf{P}$ or switching frequency compared to other PWM techniques rendering easy and economical filteration. 


\section{ACKNOWLEDGEMENT}

The authors wish to thank the BNM Institute of Technology \& its R\&D centre in Electrical \& Electronics Department for providing lab facility in simulating and analyzing proposed three phase bidirectional Buck AC converter for power quality improvement.

\section{REFERENCES}

[1]. HAMED, S.A., "Steady-state modeling, analysis, and performance of transistor-controlled ac power conditioning systems", IEEE Trans Power Electron, Vol.5, pp.305-313, 1990.

[2]. ADDOWEESH K.E., and MOHAMADEIN A.L., "Microprocessor based harmonic elimination in chopper type ac voltage regulators", IEEE Trans. Power Electron., Vol. 5, pp. 191-200, 1990.

[3]. BARBI I., FAGUNDES J.C. and KASSICK E.V., "A compact ac/ ac voltage regulator based on an ac/ac high frequency fly-back converter", IEEE Power Electron. Spec. Conf. Rec., pp.846-852, 1991.

[4]. HOFMEESTER N.H.M., VAN DEN BOSCH P.P.J. andKLAASSENS J.B., "Modeling and control of an ac/ac boost buck converter". Proceedings of European conference on Power electronics and applications, EPE'93, Vol. 7, pp. 85-89, 1993.

[5]. BHAVARAJU V.B. and ENJETI P., "A fast active power filter to correct line voltage sags", IEEE Trans. Ind. Electron., 41,(3), pp. 333-338, 1994.

[6]. KWON B.H., MIN B.D. and KIM J.H., "Novel topologies for AC choppers", IIEE proc., Electr. Power Appl., Vol.4, pp. 366-368, 1996.

[7]. SRINIVASAN S. and VENKATARAMANAN G., "Comparative Evaluation of PWM AC-AC converters", IEEE Power Electron. Spec. Conf. Rec., pp. 529-535, 1995. [8]. G.M. HASHEM and M.K. DARWISH, "Generalized symmetrical angle PWM technique for ac voltage controller', in proc. IEEE UPEC'04, pp 898-901, 2004.

[9]. A.M. Eltamaly, A.I. Alolah, R.M. Hamouda" Performance Evaluation of Three-Phase Induction Motor under Different AC Voltage Control Strategies -Part II" in IEEE explorer, 2007

\section{BIOGRAPHIES}

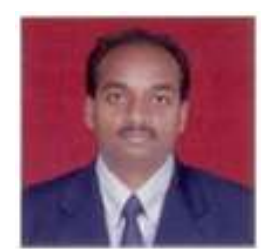

Venkatesha. K received his B.E. degree in Electrical and Electronics Engineering and the M.E. in Power electronics from Bangalore University, Bangalore in 1997 and 2005 respectively. He has secured First rank in M.E from Bangalore University. He worked as a Lecturer for Golden Valley College of engineering, Kolar Gold Fields from 2000 to 2004 . He is currently working as an Associate Professor in BNM institute of Technology, Bengaluru. $\mathrm{He}$ is pursuing $\mathrm{PhD}$ in BNMIT R\&D centre under Visvesvaraya Technological University, Belgaum. His research interests are in the areas of Power Electronics and Power Quality.

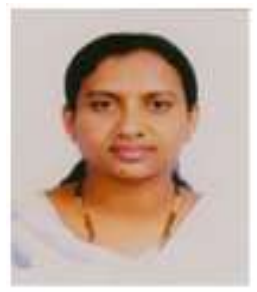

Vidya H.A received her B.E. degree in Electrical and Electronics Engineering from Mysore University, Mysore and the M.Tech. in Computer Application in Industrial Drives from Visvesvaraya Technological University, Belgaum in 1996 and 2001 respectively. She has secured First rank in M.Tech from Visvesvaraya Technological University. She has completed her $\mathrm{PhD}$ in electrical sciences in 2008 from M.S. Ramaiah R\&D centre under VTU. From 1997 to 2003, she worked as a Lecturer in KVG College of Engineering, Sullia. She worked at various capacities in BNM Institute of Technology, Bengaluru from 2003 to 2015. Currently she is heading the Department of Electrical \& Electronics Engineering, Global academy of technology, Bengaluru. Her research interests are in the areas of Signal Processing, High Voltage and Power Quality. 